- 综述・

\title{
对我国分子生态学研究近期发展战略的一些思考
}

\author{
张德兴 1,2 \\ 1 (中国科学院动物研究所, 北京 100101) \\ 2 (中国科学院北京基因组研究所，北京 100101)
}

\begin{abstract}
摘要: 分子生态学是多学科交叉的整合性研究领域, 是运用进化生物学理论解决宏观生物学问题的科学。经过半 个多世纪的发展, 本学科已日趋成熟, 它不仅已经广泛渗透到宏观生物学的众多学科领域, 而且已经成为连接和 融合很多不同学科的桥梁, 是目前最具活力的研究领域之一。其研究的范畴, 从最基础的理论和方法技术, 到格局 和模式的发现和描述, 到对过程和机制的深入探讨, 再到付诸于实践的行动和规划指导等各个层次。分子生态学 的兴起给宏观生物学带来了若干飞跃性的变化, 使宏观生物学由传统的以观察、测量和推理为主的描述性研究转 变为以从生物和种群的遗传构成的变化和历史演化背景上检验、证明科学假设及揭示机制和规律为主的机制性/ 解释性研究, 因而使得对具有普遍意义的科学规律、生态和进化过程及机制的探索成为可能。分子生态学已经进 入组学研究时代, 这使得阐明复杂生态过程、生物地理过程和适应性演化过程的机制性研究由原来难以企及的梦 想变成完全可以实现的探求; 它也带来了全新的挑战, 其中最有深远影响的将是对分子生态学研究至关重要的进 化生物学基础理论方面的突破, 例如遗传变异理论、种群分化理论、表观遗传因素的作用, 乃至进化生物学的基 本知识构架等等。这些方面的进展必将使宏观生物学迎来一场空前的革命, 并对生态学的所有分支学科产生重大 影响, 甚至催生诸如生态表观组学这样的新分支学科。对于中国科学家来说, 分子生态学组学时代的开启, 更是一 个千载难逢的机遇, 为提出和建立生命科学的新方法、新假说、新思想和新理论提供了莫大的探索空间一一此前 我们对宏观生物学方法、理论和思想的发展贡献很小。然而，限制组学时代重大突破的关键因素是理论、概念、 理念、实验方法或分析方法方面的创新和突破, 这正是我国分子生态学研究最薄弱的环节。我国教育部门应尽快 调整生命科学本科生培养的理念和方法, 以培养具备突出创新潜力的年轻一代后备人才; 同时, 科研项目资助部 门和研究人员不仅应清醒地认识本学科领域的发展态势, 更要及时调整思路, 树立新的项目管理理念和治学 理念。
\end{abstract}

关键词: 生态表观组学, 生态基因组学, 进化生物学, 表观遗传修饰, 谱系生物地理学, 群体遗传学, 选择和适应, 物种形成

\section{Unorthodox reflections on molecular ecology research in China}

De-Xing Zhang ${ }^{1,2}$

1 Institute of Zoology, Chinese Academy of Sciences, Beijing 100101

2 Beijing Institute of Genomics, Chinese Academy of Sciences, Beijing 100101

\begin{abstract}
Molecular ecology is an integrated scientific discipline that applies evolutionary theory to resolve various macroscopic biology questions. After approximately a half-century of development, it has become a well-established and active research field. It has not only penetrated numerous study areas of macroscopic biology, but also successfully bridged multiple disciplines such as ecology, physiology, geoscience and evolutionary biology. The research scope of molecular ecology ranges from developing the basic theories and methodologies, to uncovering and describing fundamental modes and patterns, to exploring processes and mechanisms, to excising research outcomes in practical applications such as conservation or pest control. The rising of molecular ecology has transformed macroscopic biology research, making it possible to leap into an epoch where systematical investigations on specific or general mechanisms are possible from joint genetic,
\end{abstract}

收稿日期: 2015-08-12 ; 接受日期: 2015-09-15

基金项目：国家自然科学基金(30730016)和中国科学院先导专项基金(XDB13030200)

* 通讯作者 Author for correspondence. E-mail: dxzhang@ioz.ac.cn, dxzhang@big.ac.cn 
ecological and evolutionary perspectives. Molecular ecology has already entered into the omic era, making many research dreams readily realisable. The omic era also brings challenges, of which the ones with the most profound influence on molecular ecology would be breakthroughs in basic evolutionary theories, such as theories of genetic variation, population differentiation, the evolutionary roles of epigenetic modification and variation, etc. Predictably, this will trigger an unprecedented revolution in biology, thus affecting undoubtedly all branches of ecology and even forging some new subdisciplines such as ecological epigenomics. For Chinese scientists, the opening of the omic era of molecular ecology has provided a rare and great opportunity for developing and establishing new methodologies, hypotheses and theories in macroscopic biology. Thus far, we have made no significant contributions. Nevertheless, theoretical, conceptual, and methodological research are the weakest areas of molecular ecology studies in China. Both research funding organizations and scientists should be clearly aware of the trends of research development and the challenges facing us; new funding management policies should be amended, and the proper research attitude and posture re-established.

Key words: ecological epigenomics, ecological genomics, evolutionary biology, epigenetic modification, phylogeography, population genetics, selection and adaptation, speciation

近二十多年是分子生态学蓬勃发展的时期。此 间, 分子生态学在很多方面推动和引领了宏观生物 学的突破性进展, 已经成为宏观生物学最具活力的 研究领域之一。近十年来我国分子生态学研究也取 得了空前的发展, 例如在青藏高原及其周边地区谱 系生物地理演化, 若干重要生物类群(包括作物、家 养动物、濒危动植物等)的种群结构、分化和谱系演 化，我国生物对第四纪气候变化的响应，山脉和高 原隆升、河流水系和海岸线变化对我国生物演化的 影响等方面开展了较系统的研究工作, 特别是近三 年以来, 对一些重要机制或科学假说的探索明显加 强, 例如生态分歧/生态适应的遗传学和表观遗传 学机制, 影响物种遗传多样性和群落物种多样性的 进化因子等, 取得了一些被国际学界关注的重要成 果。尽管如此, 我国的总体研究水平与欧美澳地区 相比还有很大差距, 在对该学科领域发展趋势的影 响上尚缺乏话语权，因此在原创性和引领性上受制 于他人。这种处境也许能从如下现象中看出: 在百 度中以精确匹配的方式搜索“分子生态学”, 找到约 29,300个相关结果，可谓繁多; 然而，对“分子生态 学”的有关描述和介绍却鱼龙混杂, 令人百味杂陈, 折射出理解和认识上的混沌。

如同整个进化生物学领域一样，分子生态学研 究正处在新的转折期, 到处存在着机遇和重大突破 口。我们能否把握住这个千载难逢的机遇, 不仅仅 取决于我们是否有足够的研究经费、是否足够勤奋, 抑或是否有看破先机的智慧，更取决于基金资助部 门的视野和科研人员自己的治学心态及学术素养。
本文阐述了笔者对分子生态学发展态势和我国在 该研究领域近期发展战略的一些思考。

\section{1 学科概述}

\section{1 什么是分子生态学?}

关于什么是分子生态学或分子生态学是什么, 不同的学者可能会有不同的理解。但是，把握其内 涵比简单地下一个定义更重要，因为任何定义都是 一种带有局限性的概括。正确认识一个学科的内涵 不仅具有概念上的重要性，而且对指导、布局和开 展相关研究也至关重要。

从研究角度概括而言, 分子生态学综合运用进 化生物学(包括但不限于分子进化和群体遗传学)的 理论、分子生物学和基因组科学的实验方法和技术 手段、统计学和数学的分析方法、计算机与信息科 学的技术和算法以及其他学科(如地学、古气候学 等)的知识, 通过研究物种和种群中的遗传变异及 表观遗传变异 (epigenetic variation，也简写为 epivariation, 即表观变异)、遗传谱系的结构、关联 特征、分布格局、形成机制和时空变化规律，探讨 生物多样性演化(包括从种群、群落到生态系统等各 个层次)、生物地理演化、物种分化、生态适应、行 为等的生态学和进化生物学机制。该学科多学科交 叉的特点可从其所研究的科学问题中略窥一斑, 例 如: 种群演化历史、种群分化和物种形成的机制、 寄主选择、配偶选择、繁殖行为、生殖方式、精子 竞争、扩散和建群、遗传谱系地理演化、遗传分化 和局部适应、生态适应的遗传基础、气候变化的生 
态学和进化生物学后果、生物对环境变化的响应机 制、遗传多样性评估、食性鉴定、受食行为、濒危 生物贸易的监测、个体和种群鉴定、外来入侵种溯 源及入侵机制、遗传修饰生物的生态风险评估、有 害生物防控等等。因此, 从这样的视角来看, 分子 群体遗传学(包括群体基因组学)、谱系生物地理学 (phylogeography)、生态基因组学、景观遗传学、系 统发生群落生态学 (phylogenetic community ecology)等都是分子生态学的分支学科。

所以，简单地说，分子生态学是多学科交叉的 整合性研究领域; 从本质上讲, 是应用进化生物学 理论解决宏观生物学问题的科学, 即进化理论的运 用。因此, 正确开展分子生态学研究的一个基本前 提是, 研究人员需要具有一定的进化生物学理论基 础, 需要掌握分析方法和算法的原理、了解其局限 性, 否则就容易出现常识性的错误 (读者可进一步 参阅 Schenekar \& Weiss, 2011; Karl et al., 2012; Meirmans, 2015)。

\section{2 分子生态学对宏观生物学的影响}

最近二十多年以来, 许多宏观生物学问题的研 究从理论机制到实际应用等方面都取得了长足的 发展, 这在很大程度上归功于分子生态学研究理念 和方法的全面引入。可以说, 分子生态学的兴起引 发了一场宏观生物学研究的革命, 给后者带来了若 干飞跃性的变化。例如:

(1)分子生态学允许我们从生命现象的基础即 DNA的分子结构及生命大分子的表观修饰等层次 上揭示生物不同生理状态、个体、种群、物种以及 更高阶元间的差别和共性, 区别遗传和非遗传、同 源和非同源(趋同、趋异等)性状和特征; 因此, 它极 大地提高了我们的分辨能力。

(2)分子生态学使得研究人员不但能定性地, 而 且可定量地描述个体、种群和物种间性状差异的遗 传基础, 对感兴趣的现象(例如个体迁移、群体、谱 系或物种起源、祖先状态和生境等等)从时间和空间 上进行追踪, 推证关联性(例如决定生态和进化适 应的遗传背景、入侵生物的地理来源等等), 追溯和 拟合导致这些变化的生理、生态、气候、地理地质、 人类活动等因素及其所影响的时空尺度。

(3)分子生态学极大地延伸了我们所能研究的 宏观生物学问题的空间跨度、时间跨度、微观尺度、 系统性、复杂性、对比能力和精确度; 因此空前地
提高了我们对具有普遍意义的科学规律、生态过程 和演化机制的探索能力和揭示能力。在这些基础上, 人类有可能在一定程度上定向改变生物多样性的 构成、调节生境、预测生物对环境的适应能力以及 生物和环境未来的演变趋势。

(4)分子生态学的众多研究实践和所取得的成 果表明, 我们对很多机制和进程的理解和了解还甚 为肤浅, 解决很多宏观生物学问题需要借鉴和了解 生物和生态系统的演化历史, 必须从生态、遗传和 进化的视角进行综合考虑和分析。

(5)分子生态学多方面地促进了原来缺乏关联 性的众多学科间的交叉融合和发展, 一方面使得许 多学科之间的界限变得模糊或消失, 另一方面催生 了新的交叉学科, 因而前所未有地改变了我们的视 野、思维方式、研究理念和习惯。

\section{2 分子生态学的发展历程}

\section{1 学科产生的历史背景回顾}

分子生态学研究萌芽于 20 世纪 50 年代, 其产生 的基本历史背景是随着DNA双螺旋结构的发现, 科 学家终于理解了产生遗传变异的分子基础和机制, 并可以直接地或间接地从分子结构水平对遗传变 异进行检测。因此, 分子生态学的发展历史就是运 用分子遗传标记和进化理论研究宏观生物学问题 的历史, 也就是分子生物学、群体遗传学、分子进 化和基因组学、生态学等交叉融合的历史(张德兴, 2002)。促成和不断加深这种融合的因素，一方面是 分子生物学技术的不断突破, 另一方面是分子进化 理论、群体遗传理论和数据分析理论和方法的建立 和逐步完善。而最近 3 年以来, 基因组测序技术的突 破使得规模化群体基因组研究成为常规手段, 并使 得对各种非孟德尔遗传的表观变异的研究可以深 入开展, 进一步强化了分子生态学的多学科交叉和 整合性的研究特征。分子生态学通过将近四十年的 实践后形成了一个综合的理论、技术和分析体系， 为 20 世纪 90 年代以来的快速发展奠定了稳固的基 础。如果说 1992年Molecular Ecology 和Molecular Phylogenetics and Evolution两个专业学术刊物的创 刊成为该学科开始得到普遍认可并广为实践的里 程碑, 那么, 随着多组学时代的到来, 分子生态学 的揭示力正在被空前地提升, 这一学科的发展正在 进入一个崭新的纪元。我们完全可以展望, 分子生 
态学正在彻底打破生态学、生理学和进化生物学之 间的隔阂, 从而使宏观生物学迎来一个前所未有的 发展机遇和创新时代。

分子生态学的发展历史一再表明, 核心分子生 物学(包括基因组学)技术的突破是推动分子生态学 研究不断普及的关键, 而理论方面的突破则是推动 分子生态学研究向更深入层次推进的关键; 保障这 两个关键能卓有成效地发挥作用的则是数据分析 方法和算法技术的突破(张德兴, 2002)。例如, 20世 纪80年代的两项划时代发明和发现, 即DNA聚合酶 链反应的发明和热稳定DNA聚合酶的发现, 使得研 究人员从此不必通过分子克隆就可以从微量样品 出发分离、制备大量用于后续操作的目的DNA样品, 并在很短时间内进行大规模样本分析, 因而分子生 态学才能得以被广泛普及。同样是 20 世纪 80 年代, 溯祖理论 (coalescent theory; 参见综述 Hudson, 1990; Wakeley, 2009)在群体遗传学中的建立, 使得 分子生态学研究有了坚实和强大的理论后盾, 极大 地提高了分子生态学研究的揭示能力。伴随这些进 展而产生的基于最大似然法、贝叶斯方法和马尔可 夫过程的分子变异和谱系关系分析算法等技术方 法的突破, 则是 20 世纪90年代以来各种层次的进化 关系研究、群体历史推断和生物地理演化研究得以 空前兴盛的关键。最新的一个例子是2011年 $\mathrm{Li}$ 和 Durbin推出的基于马氏过程的 “递次式对偶溯 祖”(pairwise sequentially Markovian coalescent, 简 称 PSMC)模型，允许基于二倍体物种一个个体的 基因组对该物种过去两三百万年的群体大小和历 史动态变化进行推断(Li \& Durbin, 2011), 为群体遗 传学和分子生态学研究开启了一扇明亮的窗户(据 2015年7月初的Web of Science检索，该方法发表不 到4年他引已达 230 余次)。

本领域的国际权威学术刊物Molecular Ecology 的发展和变化基本上映射出了分子生态学研究在 过去23年间的历史变化。该刊物1992年创刊时是双 月刊，当年仅出版 4 期，刊发 258 页; 三年半后，于 1996年改为月刊, 并且从2001年始把它所发表的分 子标记引物、技术和软件等快讯分出去成立姊妹刊 Molecular Ecology Notes (2008年更名为Molecular Ecology Resources); 2005年和2006年实际出刊各 14 期, 继而从2007年开始变为半月刊, 每年刊出 24 期, 现在每年发文已逾 6,000 页。与此同步, 刊物的学术
影响稳步上升(目前SCI 5年影响因子为6.33), 即便 在生物化学和分子生物学这样一个竞争很强、拥有 近 300 份刊物的研究领域，该刊物也进入前 $15 \%$ 的 行列。

\section{2 学科的发展阶段}

如上所述, 分子生态学基本上是伴随分子生物 学的兴起而产生, 因而从萌芽开始, 研究技术、理 论和方法的每一次突破都直接驱动该学科的发展 和进步。大体上, 分子生态学的发展历程可以分成 如下几个历史性阶段:

(1)探索阶段 $(20$ 世纪 50 年代中后期至 80 年代中 期): 特征是学科萌芽和初步形成。本阶段开启于分 子水平的群体遗传学研究, 对分子生态学的发展有 重大影响的技术成就一一同工酶电泳、限制性内切 酶酶切技术、分子克隆和DNA测序技术等关键分子 生物学技术在本阶段相继出现(为节省篇幅, 本文 不再赘列这些重大成就的参考文献，参见张德兴， 2008; 下同), 使遗传变异研究得以实现, 并可以在 群体水平进行检测; 理论上的突破主要以分子进化 的中性理论的诞生为代表，并由此引发了适应性进 化和中性进化的持久争论, 反过来极大地推动了群 体遗传学和分子进化研究; 同时, 分子钟假说的提 出和谱系进化关系重建理论、方法、算法和软件的 出现，进一步激发了分子进化和分子群体遗传学研 究的发展。然而, 在这个阶段, 虽然最基本的理论、 技术和方法都已建立，但是除了果蝇、人等模式研 究对象外, 规模化和群体水平的遗传变异研究尚不 能得以普及, 关键限制因素是以分子克隆为基础的 实验技术成本过高，效率很低。

(2)发展阶段(20世纪80年代后期至2000年)：特 征是学科快速发展并逐步形成较完整的理论、技术 和方法体系。20世纪80年代中后期DNA聚合酶链反 应(PCR)的发明和热稳定DNA聚合酶的发现引发了 一场DNA分析革命, 直接推动了分子生态学研究/ 分子群体遗传学研究真正走向大众化, 得以在众多 实验室普遍开展。从此, 研究人员不通过分子克隆 就可以从微量样品甚至各种各样的部分降解的样 品(例如历史悠久的博物馆标本、化石标本)制备大 量用于后续操作的DNA样品, 并在很短时间内进行 大规模样品分析。Molecular Ecology就是在这种时 代背景下于1992年创刊, 赋予了有近四十年研究历 史的一系列研究领域一个通俗的总称——“分子生 
态学”, 这些研究领域也在 20 世纪90年代全面进入 一个革命性的时代一一PCR时代(张德兴, 2002)。

此外, 本阶段分子遗传数据分析理论和方法也 取得了重大突破, 在分子生态学发展中具有承前启 后、举足轻重的意义。其中溯祖理论可以说是 20 世 纪后半叶理论群体遗传学的里程碑性成果, 而贝叶 斯方法和马尔可夫过程等的引入则是计算分子进 化研究的标志性事件(Yang, 2014), 极大地推进了 分子生态学研究/群体遗传学研究的发展, 空前提 升了这些学科的揭示力和可靠性。

(3)普及和转折阶段(2001年至2005年): 在这一 时期, 限制学科发展的首要因子是分子变异信息的 获取速度, 而不再是实验成本和效率, 即多态性遗 传标记的建立成为主要矛盾; 其次是数据算法和分 析软件。Molecular Ecology Notes的设立(2008年更 名为Molecular Ecology Resources) 就是一个历史标 志, 它专门快速刊发分子标记引物、技术和软件等 方面的研究成果, 标志着分子生态学研究进入一个 迅速普及的阶段。

在本阶段, 分子生态学的理论、技术和分析方 法体系都已经比较完整, 发展态势体现为由以线粒 体/叶绿体等细胞器DNA标记为主向同时注重细胞 核DNA标记转变(Zhang \& Hewitt, 2003), 由非专一 性多位点研究向特异性多位点研究转变(Zhang \& Hewitt, 2003; Schlötterer, 2004)。研究人员逐渐认识 到, 对很多宏观生物学问题的分子生态学研究, 需 要基于大量遗传位点的变异信息, 以消除生物进化 中各种随机因素的影响, 排除统计上的不确定性, 分解主要影响因子和次要影响因子, 以及解析各类 事件所影响的时间尺度和空间尺度。至此, 分子标 记、技术和软件等支撑技术的研究已成为支撑和推 动本学科发展的常规研究领域; 具有广泛影响的、 规范的系统性研究工作也已成为分子生态学研究 的基本方向。特别重要的是, 在本阶段后期, 传统 分子标记的建立和篎选方法已经成熟, 使得分子生 态学研究在众多非模式物种中得以蓬勃开展。而在 模式生物中, 海量微卫星DNA位点和单核苷酸多态 (SNP)位点被用于分子生态学研究。整个领域在对 海量细胞核SNP标记的渴望和对全基因组标记的展 望中兴旺繁荣。

(4)飞跃阶段(2006年始): 本阶段的特征是，一 方面基因组、转录组等组学技术和方法开始融入分
子生态学研究, 另一方面组学研究的主导思维和理 念也正在从生物医学迅猛拓展到生态和进化学科 领域。虽然选择2006年作为本阶段的开始年份具有 一定的个人主观性, 但是下列事实佐证了这一选择 的合理性: 第一, Molecular Ecology从2007年开始 改为半月刊, 每年刊出 24 期; 这反映出分子生态学 已经成为一个非常活跃的研究领域, 有庞大的研究 群体。第二, Molecular Ecology于2006年4月发行了 第一个生态和进化基因组学专刊 “Ecological and Evolutionary Genomics of Populations in Nature”, 以 彰显基因组学方法和手段在研究自然种群生态和 进化中的强大威力和揭示力。第三, 基因组尺度研 究的初期标志——基于表达序列标签EST (expressed sequence tags)和微阵列(microarray)的研究 是在2006-2007年开始在Molecular Ecology上大量 发表的, 含有 genomic*关键词的论文也从 2008 年开 始大幅度持续增加, 预示着基于新一代测序技术的 研究将澎湃而至(包含next-generation sequencing这 一关键词的文章第一次在该刊物发表是在 2008 年 (Diepeveen \& Salzburger, 2012))。第四, 冷泉港实验 室于2007年编辑出版了Epigenetics这一专著(Allis et $a l .$, 2007), 预示着遗传和进化研究的一个崭新纬度 的开始。而在Molecular Ecology创刊后的第22个年 头, 即2014年迎来了新一代测序技术的成熟和成本 的大幅度降低, 分子生态学研究从此真正进入(基 因)组学时代。

在表观遗传研究领域所不断涌现出的新成果 和揭示出的新问题的驱动下, 围绕各种表观变异对 生态适应和进化的潜在影响的思考和展望也开始 前所未有地冲击着进化生物学研究领域。可以预见, 表观变异很快将成为对全面阐明很多生态、进化、 生理和发育机制以及它们间的相互关联性的日益 重要的研究前沿之一。这不仅仅显示表观变异是基 因组学时代的研究前锋, 更预示着分子生态学乃至 进化生物学研究的表观组学时代已经曙光初露。

纵观分子生态学研究实践, 可以看出它由上游 研究 (upstream research) 和下游研究 (downstream research)组成。上游研究包括理论、理念、核心实 验技术、数据分析方法、算法和软件等方面的研究; 下游研究系指应用上游研究的成果分析具体生物 学问题的研究, 例如生物对青藏高原隆升的响应等 等。下游研究依赖于上游研究的成果, 而且其进展、 
成效和揭示力往往受制于上游研究的进展。

\section{3 研究领域的现状分析}

\section{1 学科领域基本现状}

如上所述, 分子生态学使宏观生物学由传统的 以观察、测量和推理为主的描述性研究转变为以从 生物和种群的遗传构成的变化和历史演化背景上 检验、证明科学假设及揭示机制和规律为主的机制 性研究(解释性研究), 因而使得对具有普遍意义的 科学规律、生态和进化过程及机制的探索成为可 能。因此, 它已经广泛渗透到宏观生物学研究的众 多领域, 成为宏观生物学不可或缺的整合性研究领 域以及连接和融合很多不同学科的桥梁, 是目前最 具活力的研究领域之一。在可以预见的将来, 它仍 将继续向所有与生态、种群和进化有关的宏观生物 学研究领域全面渗透, 并不断取得开拓性成果。

该学科已日趋成熟, 其研究范畴覆盖从最基础 的理论和方法技术研究, 到格局和模式的发现和描 述, 到对过程和机制的深入探讨, 再到付诸于实践 的行动指导等各个层次。其标志性刊物Molecular Ecology 已成为生态学领域、进化生物学领域乃至生 化和分子生物学研究领域最重要的学术期刊之一, 2014年在上述领域JCR期刊中的排名分别为前 $7.6 \%$ (11/144)、前 $10.9 \%(5 / 46)$ 和前 $10.7 \%(31 / 289)$ 。

从地域研究水平和竞争力看, 欧洲(主要是西 欧和北欧)、北美洲、大洋洲仍然是前三强, 无论在 上、下游研究的平衡性方面, 还是成果的质量和数 量方面, 抑或是研究人员的综合竞争力和数量方面 都占据着主导地位, 并且全方位地覆盖理论和方法 技术、格局和模式的发现和描述、过程和机制、行 动和规划指导等各个研究层次。他们在地史环境变 化的生物学后果、生物对历史气候变化的响应、生 物多样性的演化机制、物种形成、种群遗传学、谱 系生物地理学、选择和生态适应、转基因生物的生 态风险评估、系统发生群落生态学、食物链生态学 (营养生态学)、入侵种生态学、亲权和行为生态学、 环境基因组学、生态基因组学、人类介导的演化、 保护遗传学, 以及理论、技术、分析方法、算法和 软件等方面进行了大量系统性的研究工作。例如, 欧洲、北美和大洋洲的科学家关于环境气候变化对 生物多样性分布格局影响的系统研究已经使人类 对动植物如何应对环境变化有了前所未有的理解
(Taberlet et al., 1998; Hewitt, 2000, 2004, 2011; Schmitt, 2009; Stewart et al., 2010), 对于生物多样 性保护、农业、林业乃至城市规划都有非常重要的 意义。这些研究成果还表明, 简单地根据个别物种 对环境变化的响应特点而预测群落或生态系统的 变化/环境变化的后果会有很大的局限性。再如, 群 落层次的分子生态学研究初步表明, 物种内的遗传 多样性不仅对于该物种自身的稳定性、建群成功 率、生态适应和进化非常重要 (例如Schmitt \& Hewitt, 2004; Crawford \& Whitney, 2010), 对其所在 的群落和生态系统的稳定性也很重要; 反过来, 群 落的结构对于相关物种的遗传多样性水平和种群 结构也有重要影响(例如Nestmann et al., 2011; Whitlock, 2014; Schöb et al., 2015)。这是生态学中非 常重要又极其复杂的问题，虽然我们对此仍然所知 甚少, 但是欧美研究人员所获得的这些研究成果已 经开始为理解群落组成及其生态稳定性、生物入侵 的遗传学和生态学机制及其防控、濒危物种保护等 提供了新的实验和理论支撑。他们也同时发展和创 新了研究理念, 建立了最核心的分析理论、方法和 算法软件(例如Beaumont et al., 2010; Yang, 2014), 对推动该领域的发展发挥了至关重要的作用。可以 毫不夸张地说, 至目前为止, 分子生态学的主要进 展都来自于上述 3 个地区; 而其他地区(包括中国) 的分子生态学研究, 在理念、理论、技术和数据分 析方法以及软件上都极大地依赖于上述 3 个地区科 学家的成果。

虽然2012年以来我们对一些重要机制或科学 假说的探索明显加强, 例如关于生态分歧/生态适 应的遗传学和表观遗传学机制的研究，关于影响物 种遗传多样性和群落物种多样性的进化因子的研 究等, 研究领域因此得到一定拓展, 但是中国大陆 地区的分子生态学实践在研究方向分布上很不平 衡, 总体上比较集中于谱系生物地理学和第四纪生 物学的研究。在过去 10 年间, 中国的科研人员在这 两个相关的领域发表了大量论文，极大地丰富了我 们对中国生物地理演化格局的了解。然而，这些研 究大多局限于对结构、格局和模式等的发现和描述, 而相关的生物地理演化过程和演化机制却很少被 系统地探究，甚至缺乏可靠的时间参照体系，同时， 也存在着突出的地理区域上的不平衡和论文影响 性上的不均衡，因此极大地限制了这些研究的揭示 
力和结果的可用度。在科研项目的设置上, 尽管在 一些实验室已经建立起系统的、具有区域特色的研 究体系, 但总体上仍呈现为以个案研究和机动性研 究为主、缺乏系统性研究布局的局面。此外, 在已 发表的论文中, 实验设计以及数据和分析错误也不 少见, 有关结论因此存在疑问, 导致国际同行不敢 引用我们的结果。以2015年7月初对刊物Molecular Ecology上发表的论文的计量分析为例, 该刊物自 创刊以来共发表有199篇地址中含有“China”的论 文，其中 105 篇是以大陆地区科学家为主要作者, 另有 12 篇研究来自港台地区, 其他 82 篇则是以国外 为主、中国科学家参与的研究。把以大陆地区科学 家为主的论文跟以国外为主、中国科学家参与的论 文进行比较, 则发现: 篇均被引用次数平均约少 $27.5 \%$, 而篇均自引次数则高 $27.6 \%$; 而且还有一个 不太正常的现象——我们 $10 \%$ 的论文贡献了约 $50 \%$ 的总被引用频次, $20 \%$ 的论文贡献了 $2 / 3$ 的总被引用 频次。因此, 如果去掉这 $20 \%$ 的论文, 剩余论文的篇 均被引用次数则比国际同行低 $65.7 \%$ 。

特别重要的是, 在整个学科领域, 我们的理论 探讨极少, 对科学假说的论证以及机制性研究只是 零星地出现, 方法研究不多, 甚少参与学科领域热 点讨论, 罕有以我们为主导的引领性研究成果, 因 此, 在对该学科领域发展趋势的影响上几乎没有话 语权。前面提到过, 下游研究中任何重要成果的产 生都依赖于理论、概念、理念、实验方法或分析方 法等上游研究的创新和突破, 很遗憾的是, 这些都 是国内分子生态学研究最薄弱的环节。

\section{2 所面临的挑战}

分子生态学组学时代的开启, 使得阐明复杂生 态过程、生物地理过程和适应性演化过程的机制性 研究成为可能, 而正在蓬勃发展的表观组学研究, 一旦融合到分子生态学领域, 还将能空前地揭示环 境因子和生理因子在生命过程各个层次上的作用、 群落中不同功能单元间的相互作用以及它们对生 物进化和生态系统演化的影响。

分子生态学组学时代的开启也带来了全新的 挑战。首先是计算和分析方法的挑战。目前的一个 重要共识是, 在高遗传多态性数据和组学大数据越 来越丰富的情况下, 需要对早期基于小数据和传统 实验研究而建立起来的分析理论和方法的合理性 和成效进行反思(分子生态学半个多世纪的研究所
沉淀的技术/方法, 几乎都是基于和用于处理小数 据的), 对其局限性加以克服, 整个领域正在从传统 的对数据的经验性和总结性分析向基于模型的数 学分析和计算模拟转变(参见Nielsen \& Beaumont, 2009; Beaumont et al., 2010, 以及其中所引用的文 献)。再者是组学大数据存储/调用、对研究者实验 设计理念和视角方面的挑战, 而影响更深远的是一 些经典理论基础所面临的挑战, 例如遗传变异理 论、种群分化理论、表观遗传因素的作用, 乃至进 化生物学的基本知识构架(knowledge framework)等 等(Zhang, 2015)。因此, 分子生态学必将使宏观生 物学迎来一场前所未有的“革命性”的变化, 并对生 态学的所有分支学科产生重大影响。

对于中国科学家来说, 分子生态学组学时代的 开启, 更是一个千载难逢的机遇。它一方面为全面 检视、验证一些极其重要的、悬而未决的老科学问 题提供了全新的视角和手段, 另一方面也为提出和 解决新的科学问题, 特别是建立新的方法技术、科 学假设和理论提供了莫大的探索和思索空间。因此, 这个时代为中国科学家提供了一次树立民族声誉 的机会一一此前中国科学家对生命科学的重要理 论和思想缺乏显著贡献。问题是, 我们能否抓住这 个机遇?

\section{4 研究领域的未来发展展望}

如前文所述, 分子生态学有若干分支学科, 例 如谱系生物地理学、生态基因组学、景观遗传学、 系统发生群落生态学等等。然而, 从科学研究发展 的全程看, 其中一些研究方向, 例如谱系生物地理 学研究, 其本身只不过是研究一个系统性科学问题 所需要的阶段性要求, 如同进化关系分析或进化树 构建是谱系生物地理学研究的一个基本要求一样, 因此, 我们对其未来的发展应该有一个理性的认 识, 避免仅仅满足于研究论文的发表。

从学科领域的全局看, 分子生态学研究的重点 和难点将体现在复杂宏观生物学问题的系统研究 方面, 如生态适应的综合机制, 遗传多样性与群落 及生态系统稳定性的相互关联性，大时间尺度和空 间尺度下生物地理演化的规律和影响因子, 物种间 的相互作用, 家系结构以及行为特征对种群分化和 物种形成的影响、生物对环境的影响等等, 这些问 题一般都需在较好的研究系统下, 经过较长时间的 
研究积累, 才能取得突破。

群体基因组分析将成为核心研究方法之一 (Ellegren, 2014), 而由此衍生出来的一个研究热点 是基于全基因组数据的数据分析理论、算法和方法, 例如灵活有效快速的适应性位点检测方法、关联位 点的篮选方法、种群历史重建方法、重要种群参数 的估计方法等等。因此, 群体基因组学研究将在深 度学科交叉中发挥着不可替代的作用, 古基因组 学、景观基因组学、环境基因组学等正全面兴起, 并 将与生态、生理、地学和进化生物学等研究领域广 泛整合。

另外一个态势是更加关注从表型、遗传和表观 遗传水平综合研究正在发生的进化和生态适应事 件, 深度探索生态相互作用、生态分歧、局部适应、 物种形成和多样性演化机制等核心科学问题, 其中 在不同层次上生态和环境因子的作用机制则尤被 关注(例如外部因子如何通过影响发育、个体差别、 个体/物种间相互作用而影响生物进化和多样性 演化)。

但是，与生态学的很多其他分支学科不同，分 子生态学涵盖庞大的研究空间, 任何其他方向, 无 论是理论方面还是技术方面, 只要能取得实质性进 展, 均可成为新的热点方向, 并推动学科领域的 发展。

鉴于分子生态学研究正处在一个前所未有 的飞跃发展时期, 我国科学家应该特别关注如下 态势:

(1)在大多数分子生态学研究中, 特别是涉及到 重建进化关系、重塑种群历史、估计某种过程或重 要参数、生态适应机制、物种形成和种群分化机制 等的研究中, 多套互补型分子标记将成为必然要 求; 虽然细胞器(叶绿体、线粒体)DNA标记和微卫 星DNA标记在相当长时间内仍将具有独特优势和 一定的不可替代性, 具有基因组代表性的 (genome-wide)和全基因组水平的(whole genome)标 记, 例如SNP、基因组和转录组测序, 正成为常规研 究手段。

(2)整个学科领域将更加注重利用本学科的交 叉性和整合性的研究特点, 通过具有类群系统性和 区域系统性的规模化研究, 解决重要宏观生物学问 题, 例如地球演化中生态系统演替的机制等。因此, 对于进化和适应机制之外的很多研究, 基于单个物
种的研究的局限性将愈显突出。

(3)应注重对多物种相互作用、区域性生物多样 性演化和生态演化过程的研究，尤其是对“正在发 生的”现生生物及“已发生的”化石DNA的整合性分 子生态学研究，从而超越简单的“种群”层次的分析， 过渡到对物种、群落的动态演化机制的研究。

(4)对更深层次的进化生物学问题的研究，例如 生态适应的群体遗传机制、发育可塑性和环境可塑 性的进化机制等, 可能将备受关注。因此, 转录、 翻译等表达水平的多态性标记以及表观遗传标记 可能会逐步成为进行生态适应机制研究的重要分 子标记, 从而推动分子生态学向更高层次拓展。

(5)统计分析、群体遗传分析、基于理论模型模 拟验证将成为组学时代分子生态学研究不可或缺 的手段, 实验研究与数学模拟的结合是解决复杂宏 观生物学问题的必然趋势。对此, 我们在研究开始 之前、实验设计之初就应该作周密考虑。

(6)对分子生态学研究至关重要的进化生物学 基础理论的突破，例如前面提到的遗传变异理论、 种群分化理论、表观遗传因素的作用等等。在这些 方面, 组学时代提供了前所未有的开拓机遇。

我们虽然需要密切注意国际研究热点领域, 但 是也无需盲目追踪国际潮流。在积极加强弱势领域 的同时, 只要能利用自己的优势和特色, 开辟适合 我国实际情况的研究领域, 完全可能在显著提升我 国分子生态学研究的整体实力和综合科研竞争力 的同时，满足国家发展的战略需求，并提高我国科 学家群体的学术声誉。为此, 研究人员在项目布局 和实施方面需要注意以下问题:

(1)避免克隆式研究: 按照同一模式和实验设 计对不同物种进行平行性研究对于一些科学问题 很重要, 但并不是一个可以无限复制的研究思路。

(2)避免“大而全”式研究: 宏观生物学问题通常 都很复杂, 得到一些正确答案和线索需要进行系统 的、持续性的研究，因此试图通过一项基金就把所 有层面都进行研究从来都是不可能的。此类面面俱 到的研究不仅会大大降低研究的成效, 而且不利于 培养具有良好学术素养和科研道德的后备人才。

(3)避免盲目发表结果：原始创新思想不会凭 空产生, 需要坚实的理论知识、深遂的思考和厚实 的数据积累作依托, 因此, 应放下思想包袱, 特别 要避免只是简单地追求发表论文而忽视研究结果 
的质量; 有影响的研究成果通常需要经过一定时间 的积累和必要的沉淀。

(4)避免简单追踪和拷贝国外研究热点和模式, 注重开辟新的理念和创新思路。只有做出了引领学 科领域发展的成果才能称得上具有开创性，而缺乏 原始创新性的研究结果是不可能具有学术引领力 的; 顺着他人的足迹走虽然可能会少跌几跤, 但发 现珍宝的机会也大为减少。

此外, 鉴于在很多研究领域, 全基因组水平的 分析很快会成为很多分子生态学研究的基本要求, 而群体水平的全基因组研究依然成本昂贵, 以下 几个方面值得我国科研项目资助部门和研究人员 注意:

(1)组学测序只是研究手段, 其所产生的基因 组、转录组和表观组等组学数据只是阶段性结果, 如果没有对学科发展具有重要性的核心科学问题 作依托, 它们本身只能为公共数据积累作贡献而难 以成为重要成果。

(2)科学问题决定所需要的研究手段, 是否需要 把群体水平的全基因组分析纳入研究计划取决于 核心科学问题和研究项目的定位、规划和实验设计, 盲目地开展基因组重测序研究, 特别是在实验设计 有缺陷的情况下开展转录组测序研究会造成经费 和时间的极大浪费。尤其值得强调的是, 如上所述, 作为组学时代的研究前锋, 表观遗传变异分析将成 为分子生态学乃至整个进化生物学领域的一个重 要研究前沿, 对全面阐明生态适应、表型及发育可 塑性(环境可塑性)、物种分化、各种层次的相互作 用等诸多机制不可或缺。当然, 表观修饰体系/途径 的复杂度较高, 包含DNA/RNA甲基化、组蛋白修 饰、非编码RNA等多种类型。不仅如此, 表观修饰 途径跟DNA遗传体系不同, 在不同生物类群中有很 大差异。例如, DNA甲基化在哺乳动物中调控基因 的表达, 但果蝇中DNA甲基化似乎只局限于对转座 子的抑制。DNA甲基化、组蛋白修饰等各层次之间 存在串扰(crosstalk), 在效应上可能还与DNA遗传 多态性、代谢产物、外部环境甚至体内微生物因子 间存在交互作用(Heard \& Martienssen, 2014); 更为 有意思的是, 有些表观标记(例如染色质状态, chromatin states)在雌雄两性之间的差别甚至不亚于 在近缘种之间的差别 (例如Brown \& Bachtrog, 2014)。如此之高的复杂度导致该领域无论在表观变
异的检测方法和分析技术上，还是在因果效应的实 验验证上都还面临着巨大挑战, 甚至对于表观变异 是否能够影响适合度这样一个基本问题仍然缺乏 强有力的佐证案例(Heard \& Martienssen, 2014)。 这一方面昭示着巨大的方法、技术和理论创新研究 机遇一一而且是催生生态表观组学 (ecological epigenomics)这样一个全新学科的时代机遇, 另一 方面也提示研究人员不宜在缺乏必要技术基础和 前期研究积累的情况下草率布局生态表观组学 研究。

(3)不同领域科学家间的合作值得大力提倡、鼓 励和加强: 对于一些核心基础科学问题的研究, 为 了提高研究经费的使用效益, 充分共享基因组和其 他组学数据资源是必要的, 因此不同领域的科学家 应尽可能围绕有限数量的典型研究对象, 聚焦于重 大科学问题的不同层面, 共同设计实验, 开展兴趣 互补、多学科、系统性的研究。科研项目资助部门 应考虑设计必要的激励机制, 并对组学数据共享资 源的存储和综合开发提供资助。

(4)分子生态学研究手段能有效克服时空局限 性, 因此, 长期性或回溯性研究对于探索很多宏观 生物学问题都具有重要价值。在组学时代, 我国研 究人员需要有更深远的视野, 珍惜和综合利用已有 的布局(例如中国生物多样性监测网络等); 科研项 目资助部门需要做更多超前布局, 鼓励系统性的长 期研究。

(5)限制组学时代重大突破的关键因素是理论、 概念、理念、实验方法或数据分析方法等上游研究 的创新和突破, 而这正是我国分子生态学研究最薄 弱的环节。建议已经有较好研究基础和成果展示度 的研究团队，通过跨学科合作适当布局一些上游研 究项目, 引领我国的分子生态学研究走向一个平衡 发展的健康道路。笔者特别呼吁有更多非生物学背 景的同仁, 特别是具有统计学、数学、物理学、计 算机和信息科学背景的年轻人员, 能加入到分子生 态学(或进化生物学)的研究领域来, 加强上游部分 的研究。同时, 生命科学本科生培养和教学的理念 和方法也应进行相应调整, 迫切需要强化学生们的 宏观生物学(特别是进化生物学和生态学)知识基础, 同时加强对独立思考和探索能力的训练, 从而培养 出具备突出创新潜力的年轻一代后备人才。只有这 样, 我国的分子生态学研究竞争力才可望会有质的 
飞跃，才能迈向富有学术引领能力的明天。科研项 目资助部门应倾斜支持这方面的研究项目布局和 人才培养。

(6)最为核心的是, 我们必须树立为科学(问题) 而研究、不为论文而研究的理念, 注重研究成果对 学科发展的促进作用, 淡化对文章的数量和刊物影 响因子的追求, 科研项目资助部门和相关管理机构 更应变革科研绩效评价机制，遏制目光短浅的投机 行为。此前的一些浮躁行为已经对我国科学家群体 的学术声誉造成一定负面影响, 使一些国际同行对 在中国本土工作的科学家的科研成果的可信度产 生怀疑, 难以放心引用我们的研究结果。每位研究 人员都有责任和义务用踏实的工作和崇高的学术 素养捍卫我们自己的声誉。

\section{5 总结和展望}

分子生态学是多学科交叉的整合性研究领域, 是运用进化生物学理论解决宏观生物学问题的科 学。经过半个多世纪的发展, 本学科已日趋成熟, 其研究范畴覆盖从最基础的理论和方法技术研究, 到格局和模式的发现和描述, 到对过程和机制的深 入探讨，再到付诸于实践的行动指导等各个层次。 分子生态学的兴起引发了一场宏观生物学研究的 革命, 给后者带来了若干飞跃性的变化, 使宏观生 物学由传统的以观察、测量和推理为主的描述性研 究, 转变为以从生物和种群的遗传构成的变化和历 史演化背景上检验、证明科学假设及揭示机制和规 律为主的机制性/解释性研究, 因而使得对具有普 遍意义的科学规律、生态和进化过程及机制的探索 成为可能。因此, 它已经广泛渗透到宏观生物学研 究的众多领域, 成为连接和融合很多不同学科的桥 梁, 在宏观生物学研究中占有不可或缺的地位, 也 是目前最具活力的研究领域之一。

分子生态学组学时代的开启带来了全新的挑 战, 其中最有深远影响的将是对分子生态学研究至 关重要的进化生物学基础理论方面的突破, 例如遗 传变异理论、种群分化理论、表观遗传因素的作用, 乃至进化生物学的基本知识构架等等。这些方面的 进展必将使宏观生物学迎来一场空前的“革命”, 并 对生态学的所有分支学科产生重大影响。对于中国 科学家来说, 分子生态学组学时代的开启, 是一个 千载难逢的机遇, 为提出和建立生命科学的新假
说、新思想和新理论提供了莫大的探索空间。限制 组学时代重大突破的关键因素是理论、概念、理念、 实验方法或分析方法方面的创新和突破，这正是我 国分子生态学研究最薄弱的环节。我国教育部门应 尽快调整生命科学本科生培养的理念和方法, 以培 养具备突出创新潜力的年轻一代后备人才; 同时, 科研项目资助部门和研究人员不仅应清醒地认识 本学科领域的发展态势, 更要及时调整思路, 树立 新的项目资助和科学研究理念, 使中华民族对宏观 生物学理论和思想的创新和发展有更大贡献。

致谢: 本文从 2008 年秋季开始断断续续地写作, 部 分内容在中国科学院研究生院/中国科学院大学研 究生教学中使用, 写作后期与吉亚杰进行了充分讨 论, 表观组学方面与张勇进行了讨论, 在此对他们 所提出的建设性意见表示哀心感谢。三位匿名评审 人及责任编委提出了很好的修改意见，责任编辑对 文字进行了润色, 在此一并致谢。

\section{参考文献}

Allis CD, Jenuwein T, Reinberg D, Caparros ML (2007) Epigenetics. Cold Spring Harbor Laboratory Press, Cold Spring Harbor, New York.

Beaumont MA, Nielsen R, Robert C, Hey J, Gaggiotti O, Knowles L, Estoup A, Panchal M, Corander J, Hickerson M, Sisson SA, Fagundes N, Chikhi L, Beerli P, Vitalis R, Cornuet JM, Huelsenbeck J, Foll M, Yang ZH, Rousset F, Balding D, Excoffier L (2010) In defence of model-based inference in phylogeography. Molecular Ecology, 19, 436446.

Brown EJ, Bachtrog D (2014) The chromatin landscape of Drosophila: comparisons between species, sexes, and chromosomes. Genome Research, 24, 1125-1137.

Crawford KM, Whitney KD (2010) Population genetic diversity influences colonization success. Molecular Ecology, 19, 1253-1263.

Diepeveen ET, Salzburger V (2012) Two Decades of Molecular Ecology: where are we and where are we heading? Molecular Ecology, 21, 5656-5659.

Ellegren H (2014) Genome sequencing and population genomics in non-model organisms. Trends in Ecology and Evolution, 29, 51-63.

Heard E, Martienssen RA (2014) Transgenerational epigenetic inheritance: myths and mechanisms. Cell, 157, 95- 109.

Hewitt G (2000) The genetic legacy of Quaternary ice age. Nature, 405, 907-913.

Hewitt GM (2004) Genetic consequences of climatic oscillations in the Quaternary. Philosophical Transactions of the Royal Society of London, Series B, Biological Sciences, 359, 183-195. 
Hewitt GM (2011) Quaternary phylogeography: the roots of hybrid zones. Genetica, 139, 1-22.

Hudson RR (1990) Gene genealogies and the coalescent process. Oxford Surveys in Evolutionary Biology, 7, 1-44.

Karl SA, Toonen RJ, Grant WS, Bowen BW (2012) Common misconceptions in molecular ecology: echoes of the modern synthesis. Molecular Ecology, 21, 4171-4189.

Li H, Durbin R (2011) Inference of human population history from individual whole-genome sequences. Nature, 475, 493-496.

Meirmans PG (2015) Seven common mistakes in population genetics and how to avoid them. Molecular Ecology, 24, 3223-3231.

Nestmann S, Sretenovic Rajicic T, Dehmer KJ, Fischer M, Schumacher J, Roscher C (2011) Plant species diversity and composition of experimental grasslands affect genetic differentiation of Lolium perenne populations. Molecular Ecology, 20, 2188-2203.

Nielsen R, Beaumont MA (2009) Statistical inferences in phylogeography. Molecular Ecology, 18, 1034-1047.

Schenekar T, Weiss S (2011) High rate of calculation errors mismatch distribution analysis results in numerous false inferences of biological importance. Heredity, 107, 511-512.

Schlötterer C (2004) The evolution of molecular markers-just a matter of fashion? Nature Reviews Genetics, 5, 63-69.

Schöb C, Kerle S, Karley AJ, Morcillo L, Pakeman RJ, Newton AC, Brooker RW (2015) Intraspecific genetic diversity and composition modify species-level diversity-productivity relationships. New Phytologist, 205, 720-730.

Schmitt T (2009) Biogeographical and evolutionary importance of the European high mountain systems. Frontiers in Zoology, 6, 9 .
Schmitt T, Hewitt GM (2004) The genetic pattern of population threat and loss: a case study of butterflies. Molecular Ecology, 13, 21-31.

Stewart JR, Lister AM, Barnes I, Dalén L (2010) Refugia revisited: individualistic responses of species in space and time. Proceedings of the Royal Society of London, Series B, Biological Sciences, 277, 661-671.

Taberlet P, Fumagalli L, Wust-Saucy AG, Cosson JF (1998) Comparative phylogeography and postglacial colonization routes in Europe. Molecular Ecology, 7, 453-464.

Wakeley J (2009) Coalescent Theory: An Introduction. Roberts \& Company Publishers, Colorado.

Whitlock R (2014) Relationships between adaptive and neutral genetic diversity and ecological structure and functioning: a meta-analysis. Journal of Ecology, 102, 857-872.

Yang Z (2014) Molecular Evolution: A Statistical Approach. Oxford University Press, Oxford.

Zhang DX, Hewitt GM (2003) Nuclear DNA analyses in genetic studies of populations: Practice, problems and prospects. Molecular Ecology, 12, 563-584.

Zhang DX (张德兴) (2002) Chapter 1. Molecular Ecology. In: Modern Ecology (现代生态学) (ed. Ge F (戈峰)), pp. 7-31. Science Press, Beijing (in Chinese)

Zhang DX (张德兴) (2008) Chapter 1. Molecular Ecology. In: Modern Ecology (现代生态学), 2nd edn. (ed. Ge F (戈峰)), pp. 8-35. Science Press, Beijing. (in Chinese)

Zhang DX (2015) Are we really seeing the big picture? Some reflections on the current debates in evolutionary biology. Current Zoology, 61, 217-220.

(责任编委: 汪小全 责任编辑: 周玉荣) 